Archives de sciences sociales des religions

112 | octobre-décembre 2000

Âme et corps : conceptions de la personne

Almas y cuerpo en una tradición indígena tzeltal

Pedro Pitarch

CpenEdition

Journals

Edición electrónica

URL: http://journals.openedition.org/assr/20245

DOI: 10.4000/assr.20245

ISSN: $1777-5825$

Editor

Éditions de l'EHESS

Edición impresa

Fecha de publicación: 31 diciembre 2000

Paginación: 31-48

ISBN: 2-222-96698-1

ISSN: 0335-5985

Referencia electrónica

Pedro Pitarch, "Almas y cuerpo en una tradición indígena tzeltal », Archives de sciences sociales des religions [En línea], 112 | octobre-décembre 2000, Publicado el 19 agosto 2009, consultado el 19 abril 2019. URL : http://journals.openedition.org/assr/20245 ; DOI : 10.4000/assr.20245

Este documento fue generado automáticamente el 19 abril 2019.

(c) Archives de sciences sociales des religions 


\title{
Almas y cuerpo en una tradición indígena tzeltal
}

\author{
Pedro Pitarch
}

1 Los frailes dominicos encargados de evangelizar a los pueblos indígenas de Chiapas, hacia mediados del siglo XVI, no dejaban de maravillarse de la facilidad con que los indígenas aceptaban la nueva religión. Y en efecto, a diferencia de lo que sucedía entre otros grupos amerindios, algunos de ellos vecinos, los tzeltales no tardaron en declararse cristianos, al menos nominalmente. La decepción de los sacerdotes vino más tarde. Casi siglo y medio después de que hubiera comenzado la evangelización, un obispo de Chiapas, el dominico Francisco Nuñez de la Vega escribía una carta pastoral en la que lamentaba que los indios confundieran los ángeles de la guarda con "naguales », cierta clase de almas que por lo general son animales, meteoros y otros seres. En la carta interpelaba a los indios en estos términos :

« No creáis, hijos míos, tan estupenda mentira y desatinada patarata, porque la Majestad Divina no crió al hombre para que los brutos y rudos animales le gobernasen y mandasen ; antes sí, es de tan grande y excelente majestad el hombre que crió a los animales todos para que le sirviesen y obedeciesen como a señor propio, y ama Dios tanto a sus ovejas racionales que para defenderlas, dirigirlas y guardarlas [...] señala ángel de la guarda, y estos son espíritus tan puros que no pueden verse con ojos corporales como miráis vosotros los animales que son vuestros naguales. Pues si es indubitable en la santa fe que profesamos que son espíritus puros invisibles los ángeles ¿cómo tan ciegamente habéis creído después de bautizados, y creéis que son ángeles de guarda los astros, elementos, peces, tigres y otros brutos animales, y que Dios os los da para que os defiendan, ayuden y socorran en vuestras necesidades? $»^{1}$.

2 En la actualidad, en las oraciones que recitan los chamanes tzeltales ante el altar doméstico con el fin procurar protección a las almas animales (las mismas que denunciaba Nuñez de la Vega en su texto), algunas de estas son designadas con el término anej o anjel, evidentemente un préstamo del español ángel. Entre la perspectiva cristiana del obispo Nuñez y la indígena acerca del alma existe una diferencia radical que no ha podido ser borrada después de cinco siglos de adoctrinamiento cristiano ${ }^{2}$. En este trabajo 
quisiera tratar la concepción tzeltal de la persona a la luz del ensayo de Jérôme Baschet ${ }^{3}$ sobre las representaciones de la persona en el Occidente Medieval. Evidentemente, no se trata de un ejercicio comparativo disciplinado, ni siquiera de una comparación general; más bien procuro volver sobre la etnografía indígena manteniendo como punto de referencia el esquema europeo medieval. Pero antes de pasar a esto conviene describir, aunque sea de una manera muy sucinta, las ideas indígenas acerca de sus almas.

Los indígenas de Cancuc ${ }^{4}$, pueblo de lengua tzeltal de las montañas de Chiapas, al sur de México, suponen que los seres humanos están formados, de una parte, por un cuerpo hecho de carne y huesos- y, de otra, por un conjunto de almas ${ }^{5}$. Las almas se hallan alojadas en el interior del corazón. Obviamente el término " alma » debe entenderse aquí como una traducción de compromiso : ch'ulel, el vocablo tzeltal que designa este aspecto de la persona deriva de la raíz ch'ul, cuyo sentido cabe traducir por "santo ", « sagrado ", pero ch'ul es efectivamente « sagrado » sólo en un sentido muy estricto; es decir, ch'ul es lo radicalmente « otro » de algo. Se trata, pues, de una noción puramente relativa. Por ejemplo, la palabra ch'ul-chan, significa propiamente « lo otro de la tierra » (tierra = chan $)$, es decir, el cielo. De modo que, por lo que respecta a la persona, el/lo ch'ulel puede definirse como aquello que es « lo otro del cuerpo ». Pues bien, este " lo otro del cuerpo » se compone a su vez de tres principios anímicos: a) un minúsculo pájaro o «ave del corazón ». b) el ch'ulel, un ser al cual para distinguirlo del término más inclusivo llamaré batz'il ch'ulel, «genuino ch'ulel». Y c) los lab, un conjunto de seres de muy diversa condición ${ }^{6}$. Veamos cada uno de ellos.

El primero de estos principios anímicos se denomina en tzeltal mutil ko'tantik, literalmente «el ave de nuestro corazón $»^{7}$. En verdad es un ave: se cree que es un gallo en los hombres y una gallina en las mujeres (según otras versiones se trata de una paloma), animales idénticos a los que crían y comen en Cancuc, pero claro está de un tamaño diminuto por encontrarse dentro del corazón. Como cualquier ave de corral, el almapájaro es un ser asustadizo y atolondrado, responsable de las palpitaciones del corazón porque ante un peligro o después de un esfuerzo físico se agita y aletea. El ave es rigurosamente necesaria para permanecer con vida y no puede, no debe, abandonar el corazón porque de lo contrario el cuerpo se indispone inmediatamente y en un brevísimo espacio de tiempo muere.

5 Sin embargo, se trata de una presa codiciada por cierta clase de « demonio » (son los pále, un género de lab, es decir otra entidad anímica de los indígenas sobre la que volveremos más adelante) quien se las ingenia para extraer el ave y devorarlo. El procedimiento que siguen suscita descripciones vivísimas que en ocasiones llegan a repetirse casi palabra por palabra. Estos seres cantan o silban cerca de su víctima y el ave del corazón, seducida por el canto, se escapa a través de la boca (por la coronilla de la cabeza en otras versiones); una vez fuera del cuerpo es atrapada por el demonio quien por cuatro ocasiones la lanza al aire hasta que adquiere el tamaño normal de una gallina o gallo, la oculta entre sus ropas y se la lleva donde viven sus congéneres, en la espesura del bosque o en alguna cueva, donde se disponen a cocinarla. Allí hay mesas y sillas. Entonces, el ave es rociada con un cuenco de porcelana con agua hirviendo y luego comida.

6 La segunda clase de alma, el ch'ulel, también se aloja en el corazón y también es necesaria para la vida ${ }^{8}$. Quienes describen su aspecto coinciden en que posee el perfil de un cuerpo humano $-\mathrm{y}$, se precisa a veces, con la misma silueta que el cuerpo de su portador-, pero " sin carne ni huesos", una sombra oscura, de materia sutil. En el ch'ulel reside la memoria, los sentimientos y las emociones, es responsable de los sueños, y en él se 
origina el lenguaje. La naturaleza distinta de cada ch'ulel es, en definitiva, lo que presta a cada ser humano un " temperamento » singular. El ch'ulel existe desdoblado, copresente : reside dentro del corazón del cuerpo que vive en el pueblo de Cancuc y, simultáneamente, habita en el interior de cierta montaña, llamada ch'iibal'.

Existen cuatro ch'iibal, uno por cada linaje principal en que se hallan divididos los indígenas de Cancuc, y por consiguiente cuatro montañas. Se encuentran ubicadas fuera del valle de Cancuc - es decir, del centro del mundo - cada una en el rumbo de las cuatro esquinas del rectángulo que forma la superficie de la tierra. La forma del ch'iibal es piramidal puesto que adoptan el contorno de las montañas que los albergan. En su interior hay campos cultivados de maíz, manantiales, árboles frutales. También existe mucho dinero en moneda metálica y objetos fantásticos como relojes, radios, cámaras fotográficas, refrigeradores, teléfonos, etc. No obstante, todo lo que allí existe carece de verdadera substancia tangible, son solo sombras u objetos formados por materia sutil, la versión ch'ul de esas mercancías. Cada montaña se halla internamente dividida en trece niveles horizontales superpuestos, aunque las almas-ch'ulel solo habitan de manera permanente los tres superiores, que a su vez se distribuyen en numerosas cámaras y pasillos unidos por puertas ${ }^{10}$.

Por lo general, las descripciones indígenas del ch'iibal resaltan dos características. La primera es que en el interior de la montaña son cuidadas las almas de los niños de cada linaje. Es una suerte de enorme "jardín de infancia» donde las almas adultas, especialmente las femeninas, cuidan la de los pequeños, lo cual es importante dado que lo que le suceda al alma repercute en el cuerpo de Cancuc. La inconstancia maternal de las almas explica que los niños de carne y hueso de Cancuc lloren sin una razón aparente que lo justifique.

9 En segundo lugar, suele resaltarse el carácter de consejo político y tribunal de almas del ch'iibal. Allí, cada tres años, las almas eligen entre sí sus cargos políticos : presidente, alcaldes, regidores y policías entre otros. En las estancias superiores, sentados sobre bancos de buen tamaño y en torno a grandes mesas rectangulares, donde escriben en sus libros de registro, deliberan sobre cuestiones políticas. Por añadidura, estas autoridades juzgan, y si el ch'ulel es declarado culpable es encarcelado, y el cuerpo de Cancuc (puesto que tiene el doble del ch'ulel en el corazón) se resiente, enferma y puede llegar a morir.

Por lo que respecta a la versión del ch'ulel que reside en el corazón es capaz (a diferencia del ave del corazón) de abandonar el cuerpo sin dificultad y divagar así por el espacio, recorriendo el mundo y también exponiéndose a sus peligros. Mientras el cuerpo duerme es normal que el ch'ulel se ausente por voluntad propia (lo que al despertar se recuerda de lo que se ha soñado es resultado de las experiencias del ch'ulel). Pero también en estado de vigilia puede evadirse a causa de un sobresalto, de un arrebato, como resultado de un esfuerzo o excitación fuertes, incluso, antojadizo como es, por simple capricho. Esta última posibilidad es especialmente común entre los niños pequeños, a cuyos cuerpos el ch'ulel no se ha habituado todavía y en donde es especialmente sensible a cualquier demostración de irritación de los padres con su hijo. Sin embargo no es el ch'ulel el ser trastornado por la separación, puesto que es inmune a cualquier deterioro o daño físico y solo recibe daños "emocionales", sino el cuerpo: la ausencia prolongada del ch'ulel produce «desánimo" en la persona, que avanza con el tiempo de separación y cuya intensidad depende de la propia fuerza corporal, hasta que el cuerpo acaba por fin falleciendo. Este estado puede prolongarse durante varios meses y en casos excepcionales hasta por uno o dos años. 
11 La ausencia de este alma se debe a veces a que se pierde y no encuentra el camino de vuelta. Pero en otros casos, más graves, algunos seres sobrenaturales apresan el ch'ulel cuando este deambula fuera del cuerpo o se las ingenian para hacerle salir engañándole. Le dicen por ejemplo: "vamos a ver una fiesta en tal lugar, habrá música y aguardiente...» (siempre emocional, el ch'ulel siente un irresistible gusto por el aguardiente, la música, las guirnaldas de papel...) y una vez fuera le atrapan.

Los títulos de algunos ensalmos de curación chamánica, los de la clase chukel, " cárcel », dan una idea de en qué extraños y recónditos lugares aprisionan el ch'ulel sus adversarios lab. Por ejemplo : yut lumil chukel (dentro de la tierra); oxyoket chukel (en la piedra mayor de las tres que componen el hogar doméstico); chukel ta ni'te' (en los brotes tiernos de la copa de los árboles, probablemente pinos); chukel ta kamolch 'en (en el interior de un fragmento de roca desprendido de la entrada de una cueva); chukel ta nej ajawchan (en uno de los cascabeles de una serpiente de cascabel) ; chukel ta kurus (en el interior de una cruz de madera) ;tz'unuba chukel (en el hoyo de las semillas de maíz de algún campo recién sembrado) ; chukel ta yolbej (en mitad de un sendero); chukel ta jol sna riox (en el nicho superior de la fachada de la iglesia de Cancuc o de otros pueblos); chukel ta yan mexa manojel (en el interior del cajón que guarda la imagen del « Santo Entierro », dentro de la iglesia). Algunas de estas prisiones son calientes y otras frías, lo que produce en el cuerpo respectivamente fiebre o frío, aunque no es raro que los lab trasladen el ch'ulel de uno a otro de estos lugares para dificultar al chamán la comprensión de los síntomas.

Hasta aquí las dos primeras clases de almas, el ave del corazón y el ch'ulel. El corazón de los cancuqueros contiene todavía un tercer tipo de alma que se conoce como lab. Los lab existen igualmente desdoblados, copresentes : se trata de criaturas « reales » - un animal, por ejemplo - que habitan el mundo exterior, pero que además están duplicados en el corazón humano, con idéntico perfil que el del ser que habita fuera, pero aquí " gaseiformes ». De este tipo de almas los cancuqueros tienen como mínimo una y como máximo trece, pero lo más común es tener dos o tres. Los lab son de muy diversa condición y no existe una clasificación rigurosa de sus tipos. Grosso modo se distinguen en las clases siguientes :

14 a) «Animales ». Prácticamente todos los animales pueden ser lab de un indígena : aves (colibrí, águila, buitre...), insectos (especialmente ciertas hormigas y orugas), mamíferos (zarigüeya, zorro...), roedores (ardillas, ratas silvestres...). No obstante los lab más citados son los felinos : ocelote, puma, jaguar, gato doméstico. Desde luego si algún percance le sucede al animal, lo mismo le ocurrirá a la persona de Cancuc. Por otra parte, no todos los individuos animales son lab, solo algunos son verdaderamente sénte (del español " gente »), pero nada hay en estos últimos que a primera vista les identifique como tales. Su naturaleza no difiere en esencia del resto de los individuos de su especie, entre los que viven ; idéntico aspecto, el mismo habitat, iguales o muy parecidos hábitos (si bien en la zoología indígena los animales se comportan muy humanamente) : los jaguares viven en la espesura de la selvas de la tierra caliente que se encuentran al norte y este de Cancuc ; los pumas en los bosques y montañas más altas ; los gatos en cualquier pueblo del mundo, y así.

15 b) «Seres fluviales ». Por lo general su cuerpo es el de una serpiente, pero cuya cabeza tiene la forma de algún instrumento metálico ${ }^{11}$. Así : machete, hacha pico, marro, tijera, pala, aguja, rejilla, etc. Viven en pozas profundas de ríos y lagunas y son responsables de la erosión del paisaje y de los súbitos corrimientos de tierra. 
16 c) « Meteoros ». Entre ellos se cuentan los vientos, los rayos verdes, el relámpago, el arco iris y las bolas de fuego. Es muy común que vientos y rayos lab luchen unos contra otros : ordinariamente viven dentro de ciertas montañas, pero cuando comienza la estación de las lluvias salen a combatir. Si, por ejemplo, un rayo - disparan con un mosquete - acierta a un viento, en ese instante el cuerpo de algún indígena aparecerá parcial o totalmente quemado, y es cabe sospechar que uno de sus lab era un viento.

d) « Dadores de enfermedad ». El último tipo de almas lab reúne seres másdispares, pero sólo en apariencia puesto que todos ellos comparten la condición de serak' chamel, « dador de enfermedad». Si los lab mencionados hasta el momento soncapaces en algún caso de producir daño a los hombres de carne y hueso, en la mayoríade las ocasiones el riesgo que implican es pasivo, esto es, alguien enferma comoresultado que su lab ha sido muerto o afectado. Los de esta última clase, sin embargo,difieren del resto por entregarse activamente a la fabricación de enfermedad, son lab homicidas, pese a que sus motivos no siempre sean comprensibles. (El elemento comúna esta serie de lab «dadores de enfermedad» es la facultad del lenguaje. El resto delos lab pueden disponer de «lenguajes" propios con los que se comunican entre sí, oa lo sumo "entienden » pasivamente el lenguaje humano, pero no son capaces dearticularlo. Y las palabras son el principal vehículo de enfermedad).

18 El más destacado de estos seres se conoce como pále, del español "padre cura », también citado en las oraciones como kelérico, "clérigo". Miden un metro de altura aproximadamente, son bastante gordos, calvos, con una vestidura que les cubre hasta los tobillos y calzan zapatos. No cabe duda que son sacerdotes católicos, con los que explícitamente se comparan. En realidad hay varios tipos de pále. Los más comunes son los "padre negro». Su ropa es de color negro y en opinión de algunos sólo actúan durante la noche. En cambio, el « padre diurno » se cubre con ropa blanca y su cabeza no tiene pelo excepto en una estrecha franja por encima de las orejas; a veces lleva una capucha con la que se cubre la cabeza y rostro. Los jefes de los pále son los wispa, " obispo », de aspecto más rechoncho, probablemente porque visten varias prendas de ropa superpuestas de distinto color y unos zapatos negros pero muy brillantes. Un cuarto tipo de sacerdote es mucho más raro: el jesúta, es decir, «jesuíta ». Su apariencia es también distinta; se ignora cómo viste, pero es más alto y de una extraordinaria delgadez, de ojos hundidos y una nariz estrecha y prominente. En cualquiera de sus versiones, a los pále les domina un irreprimible deseo de comer carne. Tienen predilección por las aves de corral, específicamente por el ave del corazón, esto es, fatídicamente, el alma de cada indígena. $Y$ en efecto son precisamente estos seres los que -como vimos anteriormente- extraen el ave del corazón (gallo o gallina) para cocerla y comérsela.

Pero en esta categoría de lab - « dadores de enfermedad» - hay otros seres. Los eskiribano (« escribano») son en varios aspectos parecidos a los pále. Entre ellos se encuentran los nompere, del español «nombre »; se trata también de un enano, vestido con calzones y camisa de color negro y un sombrero plano llamado birete («birrete»). En una de sus manos sostiene una pluma de ave y en la otra un cuaderno (jun : libro, cuaderno, papel escrito o para escribir). Como su nombre indica, Nombre da enfermedad escribiendo los nombres de sus víctimas ; dice, «bueno, ¿veamos a quién doy enfermedad?», entonces se sienta y cuidadosamente inscribe el nombre, el nombre tzeltal, en una lista, y es suficiente con este único acto para que enferme el nominado. Del «profesor » (porvisor, povisol), un segundo tipo de escribano, es más difícil obtener una descripción precisa; 
parecido a un maestro de escuela, con el que se equipara, de él se dice que remite la enfermedad leyendo en alta voz un libro, al parecer sin seleccionar previamente su víctima. El «castellano » (kaxlan), otra clase de lab, parece indudablemente un ranchero mestizo, si bien los detalles de su indumentaria varían con las descripciones; suele llevar un sombrero y pantalones de cuero y camisa y en ocasiones espuelas de metal brillante y gafas de sol ; cuando es visto en sueños monta a caballo.

Igualmente las ovejas (tumin chij, literalmente " venado de algodón ») y cabras pertenecen a este grupo. Tampoco en este caso todos estos animales son lab, en su mayoría son simples animales, ahora bien, si uno se fija detenidamente es posible advertir por un instante que la mirada de algunos parece humana. También son «dadores de enfermedad » los buhos y lechuzas.

Además nuevas formas de lab han venido a engrosar este grupo de dadores de enfermedad. Desde hace ya varios años durante la noche se escucha música y cánticos muy parecidos a los que interpretan los indígenas protestantes en sus templos, o bien que circulan en cintas magnetofónicas : música de guitarra, guitarrón y acordeón, con el tipo de ritmo norteño mexicano, pero que no son sino cantos religiosos evangélicos. Todavía antes, hace unos veinte o treinta años, hizo su aparición una especie de lab, los me'tiktatik ( madres-padres »), que con el tiempo se ha revelado enormemente mórbida. Al parecer su figura es la de hombres y mujeres ancianas con el cabello y barba encanecidos, pero invisibles. Su costumbre consiste en sentarse en pequeñas sillas alrededor de una mesa en mitad de los caminos para comer y beber : pollo, sopa, aguardiente, café ; de tal modo que cualquier caminante se arriesga a volcar inadvertidamente los alimentos, invisibles también. En represalia los me'tiktatik sustraen su ch'ulel para obtener de las ceremonias de curación alimentos al menos equivalentes. Los lab me'tiktatik son lum, « tierra » (pero nada tienen que ver con los señores de la montaña), en cierto modo emanaciones de ésta bajo figura humana. En consecuencia son almas minerales.

Las almas lab se hallan diseminados por la superficie del mundo. Pero, como se recordará, se encuentran asimismo duplicados dentro del corazón y bajo ciertas condiciones pueden salir del cuerpo, lo cual viene a añadir todo un conjunto nuevo de problemas. Puede suceder que mientras el cuerpo duerme el lab « interior» salga por la boca, deambule entre las casas, cometa sus fechorías de modo semejante a como lo hacen los lab " exteriores" y retorne finalmente al corazón. (Durante su ausencia puede ser que el cuerpo se haya colocado boca abajo y el lab tenga dificultades para reintroducirse por la boca). Lógicamente cualquier percance que sufra esta segunda versión de lab repercute igualmente en el cuerpo. No es que la voluntad del cuerpo participe en la maniobra, de hecho ni siquiera cobra conciencia de lo que está sucediendo, sino que es el lab quien emerge por propia decisión. Este pormenor es crucial. Aquí no interviene metamorfosis ninguna : el lab forma parte del talel de la persona en cuestión : la raíz de la palabra es tal, " venir », y, aplicado a una persona, tiene el sentido de « lo que le viene dado ».

Aunque abordaré enseguida el comentario de este material en relación el ensayo de J. Baschet sobre las almas medievales, conviene hacer una observación preliminar acerca de la descripción etnográfica que acabo de presentar.

24 El esquema elemental sobre las almas que he expuesto en realidad no existe como tal entre los indígenas de Cancuc. Se trata de, por así decir, un guión virtual, una solución de compromiso para facilitar una exposición que de otro modo, si recogiera las distintas variantes y sobre todo la casuística sobre las almas, resultaría imposible presentarla en unas pocas paginas. De hecho, no existe un contenido nacional susceptible de ser 
transmitido formalmente, un corpus doctrinario. La producción, transmisión y circulación de saber relativo a la persona es un proceso inmerso en la práctica, en lugar de en el discurso (y cuando aflora en el discurso, lo hace de manera muy fragmentaria). Mucho de lo que se sabe sobre el universo de las almas tiene un carácter contextual, relacionado con actividades rutinarias : el chismorreo, la interpretación de los sueños, la exploración del carácter individual o las actividades médicas de curación. Por otra parte, una buena dosis de la información que obtuve sobre este campo es el resultado de mi trabajo directo con los ch'abajometik de Cancuc, es decir, chamanes especializados en la recuperación de almas ${ }^{12}$. Ahora bien, a pesar de que los cancuqueros dan por supuesto que los chamanes tienen un conocimiento mayor y más detallado del mundo de las almas, el saber sobre estas no constituye propiamente un saber esotérico; circula prácticamente entre toda la población : jóvenes, mujeres, ancianos. En efecto, las almas absorben una buena parte de la curiosidad, inquietud y reflexión de los cancuqueros. Sin duda hay en juego muchas relaciones sociales y personales cuyos hilos atraviesan directa o subrepticiamente este campo de saber y lo convierten en objeto de una intensísima atracción. Pero, quizá debido a ello, este no es un campo sobre el que sea fácil hablar directamente. Por decirlo así, es un saber público y a la vez secreto : hablar de las almas exige una enorme discreción y habitualmente se hace de manera oblicua, sobreentendida; es un saber implicado más que explicado.

Entiendo que la representación europea de la persona, medieval o no, se debe fundamentalmente a un conocimiento canónico, normalmente expresado por escrito. Se trata de doctrinas, en el sentido de un conjunto orgánico, sistemático, de ideas que se exponen. No así en el mundo tzeltal. Sin duda se debe a que estamos tratando con campesinos iletrados. Pero probablemente hay algo más fundamental. Una forma de razonamiento en la que no hay lugar para la controversia doctrinaria. Desde un punto de vista indígena mesoamericano es prácticamente imposible una herejía religiosa. Por ejemplo, un personaje como el de Menocchio - el molinero italiano sobre el que escribió Cario Ginzburg ${ }^{13}$ - que disputa con los inquisidores en sus mismos términos, resulta difícil de imaginar en el mundo indígena de Chiapas. A lo largo del período colonial, la Iglesia Católica no podía enfrentarse - como tampoco pueden hacerlo las iglesias evangélicas hoy en día - a una doctrina indígena de la naturaleza humana que pudiera combatir de acuerdo con las convenciones europeas. Hay, pues, una asimetría entre ambos mundos : no se enfrentan dos religiones, como en Europa. La indígena no es una religión.

Hemos visto como, en la concepción tzeltal, la persona está constituida por un heterogéneo conjunto de seres : animales, meteoros, espíritus, objetos, o monstruos. Si los indígenas de " carne y hueso » viven sobre la superficie de la tierra, la mayoría de estas almas o coherencias son criaturas atmosféricas o habitan en las vías fluviales. En el caso de que sean animales terrestres, la mayoría de las especies suelen encontrarse lejos del pueblo de Cancuc, frecuentemente en la "tierra caliente", en el dominio de la selva pluviosa cuyo calor sofocante consideran los cancuqueros que es insalubre e inapropiado para la vida civilizada. $O$ bien viven en las ciudades mexicanas ; o más raramente algunas especies de lab viven en tierra fría pero fuera de las áreas habitadas o transitadas por los cancuqueros de carne y hueso, en los bosques o sitios encumbradas de difícil acceso. El mundo, pues, se halla plegado sobre la persona. Mediante un complejo juego de desdoblamientos y copresencias, el cosmos se encuentra fragmentariamente repetido en el interior del cuerpo. $\mathrm{Y}$ en ese pliegue del afuera también han quedado retenidos 
fragmentos del pasado; seres que en algunos casos, como el de las almas lab que son curas, obispos o jesuítas, remiten a un pasado histórico ${ }^{14}$.

Ahora bien, si, en la representación indígena, la persona está compuesta por una miríada de seres, podemos entonces preguntarnos ¿en qué se distinguen los humanos de otros seres animados? O dicho de otro modo ¿en qué reside la especificidad humana de los seres humanos? A decir verdad, pese a que llevo ya algún tiempo trabajando sobre las concepciones indígenas de la persona, no me he hecho esta pregunta hasta que he leído el ensayo de Jérôme Baschet. En la representación cristiana medieval, aunque la « naturaleza humana » está formada por la unión necesaria entre el cuerpo y el alma, la persona tiende a identificarse con su alma. Lo que dota de su condición humana a los hombres es estar en posesión de un alma, o al menos, que esta se distinga por poseer una facultad elevada, intelectual o racional que acerca el hombre a Dios. Esta dimensión del alma es la que le diferencia del resto de los seres vivos, bestias o plantas, con los que el hombre tiene en común únicamente la naturaleza del cuerpo material y algunas facultades inferiores del alma o quizá un mismo principio vital.

Quiero sugerir aquí que en la perspectiva tzeltal se produce una relación inversa. Aquello que otorga a la persona su condición propiamente humana es el cuerpo. Las almas nada tienen de específicamente humano, pertenecen al mundo de los animales, de los espíritus y de otros fenómenos naturales. $\mathrm{O}$ de manera más precisa, las almas son estos seres. En cambio, es el cuerpo humano, que pliega el afuera y el pasado, el que produce un aquí y un ahora, que confiere una condición característica a los hombres.

Los indígenas suponen que las entidades anímicas se introducen en el feto mientras este se desarrolla en el seno materno. El origen preciso de estas almas varía algo en las explicaciones de los informantes, pero la suposición más extendida parece ser la de que el ch'ulel procede del nivel superior de los trece que forman el cielo (el signo de su llegada son los primeros movimientos del feto); por su parte, los lab provienen de un miembro del mismo linaje que el niño, que los transfiere a este en el instante de la muerte ; y el ave del corazón - aunque en este punto hay más dudas - parece desarrollarse paralelamente al embrión. Ahora bien, en el interior del vientre materno el feto se encuentra "desplegado ", como una piel a la que se le ha dado la vuelta. Solo en el momento del nacimiento el cuerpo se pliega, aprisionando de este modo las almas que ha recibido. Así pues, la figura del pliegue debe entenderse aquí de modo totalmente literal.

A diferencia de las almas, que son dadas (son el talel de una persona, es decir, literalmente «lo que le viene dado »), el cuerpo indígena se hace. El cuerpo se va lentamente formando a lo largo de la vida individual y, en efecto, la cultura tzeltal deposita un enorme esfuerzo en su construcción : en el control de los gestos, del lenguaje apropiado y del uso correcto de la vestimenta. Pero seguramente es la alimentación la función que ejerce un papel mayor en la formación del cuerpo. Se funda en la idea de que el cuerpo encarna, literalmente, aquello que consume. Por tanto la carne del cuerpo indígena esta hecha de maíz y frijol, los elementos básicos de la dieta de los campesinos de Chiapas (en las oraciones el maíz es designado con las expresiones ch'ul chu', ch'ul bak'etal, «sagrado pecho, sagrada carne). El consumo continuado de ctro tipo de alimento resultaría en una muy real transformación corporal. Por ejemplo, siguiendo una lógica alimentaria en el fondo muy similar a la tzeltal, durante el siglo XVI entre los nahuas del centro de México, un jefe indígena llamado Juan Tetón que combatía la dominación española prevenía en estos términos a los demás indígenas : 
« Oigan ustedes [...] ¿ya saben lo que andan diciendo nuestros abuelos? Cuando sea nuestra atadura de años, habrá completa oscuridad, bajaran los tzitzime, nos comerán y habrá transformación. Los que se bautizaron, los que creyeron en Dios, se mudaran en otra cosa. El que come carne de vaca en eso mismo se convertirá ; el que come carne de puerco, en eso mismo se convertirá; el que come carne de carnero, en eso mismo se convertirá y andará vestido de su zalea; el que come carne de gallo en eso mismo se convertirá. Todos, en aquello que es su comida $»^{15}$.

31 La cocina, es decir el principal productor de los cuerpos, es lo que diferencia a los indígenas tanto de los animales o los espíritus como de otros grupos humanos - y por tanto, no exactamente humanos - como los europeos.

32 Si el nacimiento supone un pliegue del afuera, la muerte del cuerpo es el momento de despliegue en que el contenido del corazón es devuelto al mundo. Entre los tzeltales no existe demasiado interés por conocer el destino póstumo de las entidades anímicas, tal y como sucede respecto de su origen. Sin embargo, la idea más extendida, aunque de nuevo con variaciones, parece ser la siguiente : el ave del corazón es liberada (por la coronilla de la cabeza) al mundo donde finalmente será devorada por un espíritu o un animal salvaje desapareciendo así por completo. El ch'ulel abandona también el cuerpo y después de unos días $(20,40)$ se introduce en el interior de la tierra por la cruz del atrio de la iglesia (o bien tras el altar mayor de la iglesia) hasta que va a parar a un lugar llamado k'atinbak, que será su residencia perpetua. Este es un lugar oscuro, frío y húmedo, pero fuera de la incomodidad que esto supone no es un lugar de sufrimiento y menos aun de tormento infligido. En cuanto a las almas lab, estas son transmitidas por una persona cuya muerte sea inminente a un niño mientras se encuentra en el vientre materno, bajo la condición que sea miembro de su mismo linaje. Se dice que a veces se pueden ver estas almas en forma gaseosa cuando salen por la boca en el momento de expirar.

La calidad moral de la persona durante su vida - lo que equivale a decir su educación y compostura corporales - no determina en nada el destino final de sus almas: estas tendrán el mismo destino para todos. No obstante, existen destinos alternativos para el ch'ulel de acuerdo con la forma en que se produce la muerte. Si la persona es asesinada, su ch'ulel no termina en el k'atinbak si no que se introduce en alguna montaña donde trabajará como sirviente de uno de los poderosos « dueños » sobrenaturales que en ellas residen. En cambio, si la persona muere en una acción militar o, entre las mujeres, por causa del parto, el ch'ulel asciende al cielo y acompaña al sol en su recorrido (se afirma a veces que las estrellas son los ch'ulel de quienes han muerto así). Estas son muertes prematuras y no poseen ninguna connotación gloriosa, tal vez por que han truncado violentamente el desarrollo pleno de una vida dejándola a medio hacerse. Lo que parece importar a los tzeltales es la forma en que el cuerpo termina ${ }^{16}$.

El cuerpo, que es enterrado, se descompone y desaparece para siempre. Si, conforme a mi argumento, la condición humana reside en el cuerpo, la muerte implica la deshumanización de la persona. Lo que de ella queda son los fragmentos menos específicamente humanos. Los componentes de la persona no desaparecen del todo tras la muerte, al igual que sucede en el cristianismo. Pero en este último lo que resta tras la muerte es el componente más humano (el alma), mientras en la idea indígena lo que queda es lo menos humano (las almas). A pesar de ciertas reticencias a individualizar completamente el alma, las representaciones cristianas medievales « doivent assurer au contraire, par-delà la mort, une forte continuité de la personne, de sorte que la rétribution dans l'au-delà s'applique bien à l'être qui, ici-bas, en a mérité les rigueurs ou les joies $»^{17}$. Entre los indígenas, sin un cuerpo capaz de mantener unidas los 
heterogéneos fragmentos anímicos, estos se dispersan por el cosmos sin que ninguno de ellos en particular pueda privilegiarse como la continuación de la persona en el «más allá ».

Con el fin del cuerpo se suprime la posibilidad de reunificación de la persona. La doctrina de la resurrección general de los cuerpos sigue siendo totalmente extraña a los tzeltales, pese a que durante casi 450 años han estado expuestos a esta idea cristiana. En las últimas décadas, por ejemplo, los misioneros protestantes - a cuyas iglesias los indígenas de Chiapas se han adherido en gran número - han vuelto a insistir en el conocimiento del Juicio Final. Pero la reacción indígena es muy instructiva. Para los indígenas convertidos al protestantismo afirmar públicamente una cosa así es un motivo de embarazo, y lo evitan todo cuanto pueden. Para los indígenas no convertidos es un motivo de burla : la idea de que llegue el tiempo en que los cuerpos de los muertos se levantarán de sus tumbas y ascenderán al cielo con toda su carne (aquí se exclama : jel cuerpo entero!) es algo que, de puro absurdo, da risa. Y la importancia de este rechazo explícito es tanto mayor cuanto que, como mencionaba anteriormente, entre los tzeltales las discusiones construyendo de carácter doctrinario son prácticamente inexistentes. Por lo demás, « el cuerpo glorioso" cristiano, que incluso en sus definiciones doctrinarias más "corporales" carece de funciones alimentarias y sexuales, difícilmente puede considerarse en una perspectiva indígena propiamente un cuerpo. Tal y como sugería antes, el cuerpo tzeltal no es tanto una substancia carnal como el producto de los hábitos culturales que lo van $^{18}$, significativamente aquellos que se encuentran ausentes en los cuerpos resucitados del Cielo cristiano.

El esquema de antropología tzeltal que he sugerido - la condición humana reside en el cuerpo, las almas remiten al mundo no humano - es, sin embargo, demasiado simple. Como vimos en la descripción etnográfica, entre los tzeltales una de las almas - el ch'ulel tiene el mismo perfil que el cuerpo que la aloja. Desde luego no puedeconsiderarse un cuerpo en miniatura, pues está formado por una substancia gaseosa,materia sutil, que no se encuentra sujeta a las mismas circunstancias que el cuerpofísico (sale del cuerpo, se desplaza en el espacio y en el tiempo sin dificultad). Encuanto a su grado de humanidad, los hábitos del ch'ulel son inciertos para determinarlo; en muchos aspectos estos son más europeos que indígenas, y por tanto de unahumanidad parcial. Pero, por otra parte, está muy lejos de la galería de criaturas - animales, meteoros y otros - que compone las almas lab. Así pues, el ch'ulel pareceocupar una posición intermedia entre las almas lab y el cuerpo. En este punto quizáexiste una coincidencia esencial entre las representaciones indígenas y medievales dela persona. También en estas últimas, como demuestra J. Baschet, existe una tendenciaa pensar en « un niveau intermédiaire entre la matière et l'intellection, dont l'objet estd'articuler le corporel et le spirituel $»^{19}$. Pareciera que en ambos casos existiera lanecesidad de evitar un modelo estrictamente dualista.

Para terminar, como observa J. Baschet, la diferencia entre la antropología cristiana medieval y la indígena tzeltal es en esencia aquella que separa el monoteísmo del politeísmo. Si en el cristianismo se favorece la relación entre el alma y Dios, en el mundo indígena se favorece la relación entre las almas y el mundo. Por lo demás, en el caso cristiano la relación entre el cuerpo y el alma, el hombre y Dios, es una relación fundamentalmente jerárquica. En el mundo indígena, sin embargo, no existen relaciones permanentes de superordinación y subordinación. El carácter moral de una persona se refleja en su bienestar físico y en el dominio de sí durante su vida ; y esto a su vez pasa por establecer unas relaciones aceptables, a través de complejas formas de reciprocidad e 
intercambio, con las especies naturales, las fuerzas místicas y los demás seres humanos. Puede decirse que existe una jerarquía, pero esta es relativa, cambia conforme a las circunstancias y contexto en que se produce la relación entre el hombre y el mundo. Como afirma Christopher Crocker respecto de los indios Bororo del Mato Grosso, « el ser humano no es más que lo animales ni menos que los ángeles $»^{20}$. Y esta es una perspectiva radicalmente distinta de aquella que instruía el obispo Nuñez de la Vega a los indios de Chiapas en el texto citado al comienzo.

Alcades de Cancuc en un receso de una ceremonia en la iglesia (1990).

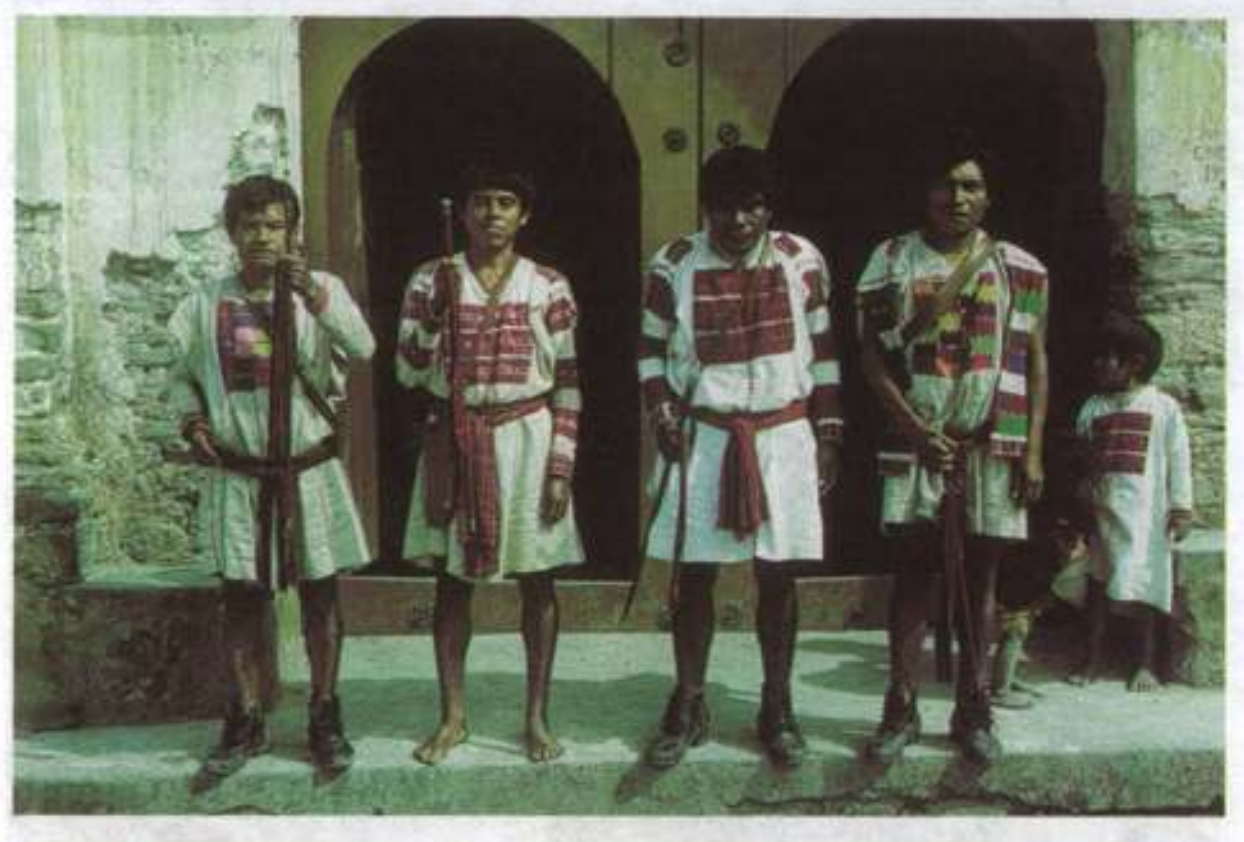


Altar doméstico durante la ceremonia de recuperación del ch'ulel.

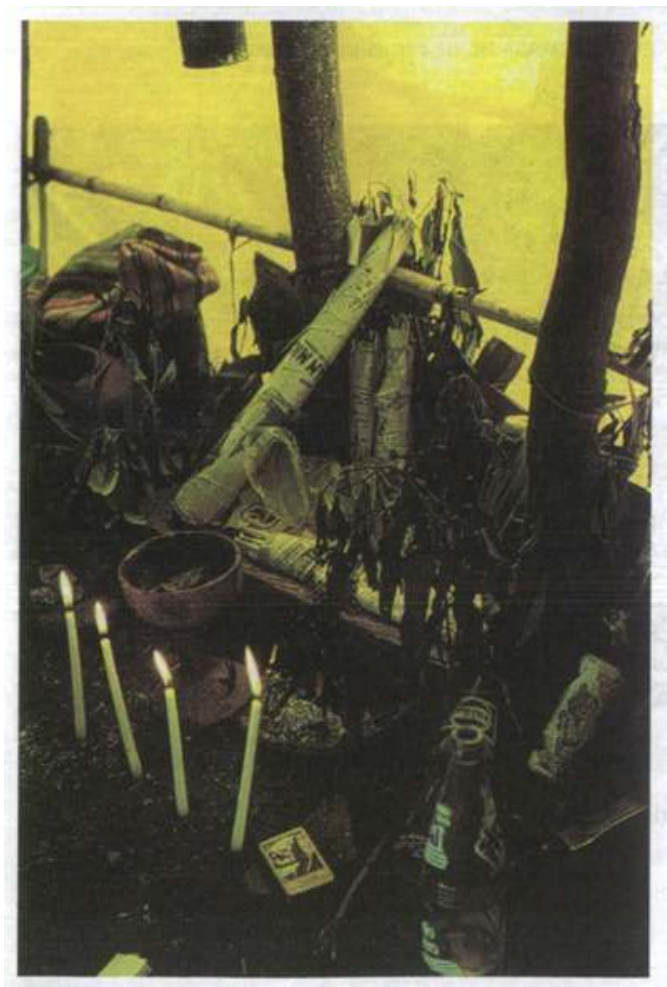

Las ramas de pino convencionales han sido substituidas por ramas de la planta de café, pues éste es el secuestrador del alma.

Embriaguez durante la ceremonia de reposición del ch'ulel.




Familia Lol, paraje de Chakte' (1989).

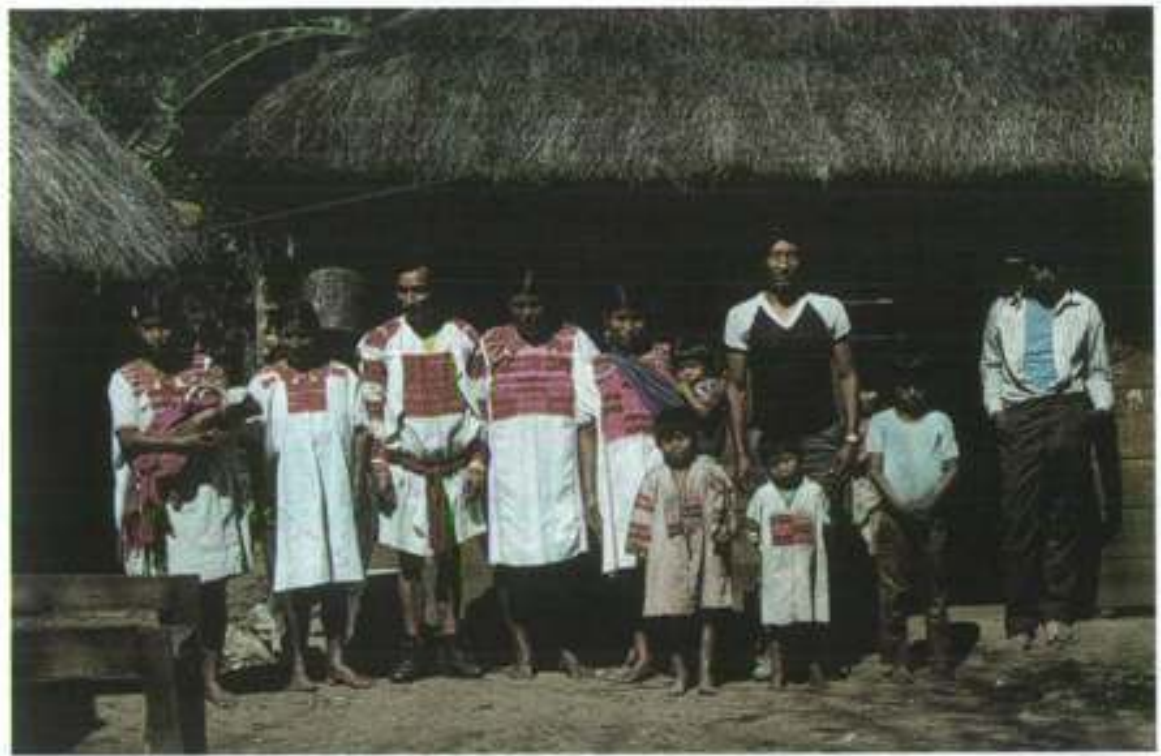

\section{Enterramiento reciente (1989).}

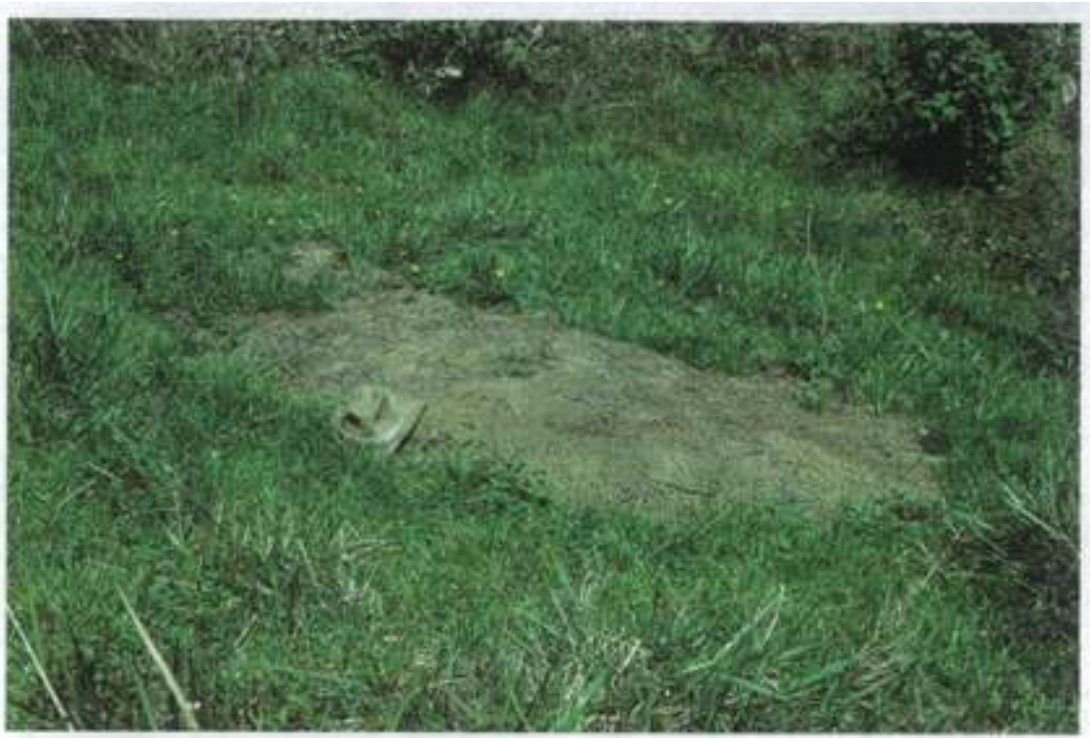

Después de algún tiempo el sombrero habrá desaparecido y sólo se recordará el lugar por el color de la hierba ; tras varios años el recuerdo del lugar desaparecerá por completo y con él la identidad singular del muerto. 
Muñeca de maíz : « el cuerpo encarna, literalmente, aquello de lo que se alimenta ».



\section{BIBLIOGRAFÍA}

BASCHET Jérôme, « Âme et corps dans l'Occident Médiéval : Une dualité dynamique, entre pluralité et dualisme ", Archives de Sciences Sociales des Religions, n 112 (oct.-déc), 2000, pp. 5-30 BRETON Alain, BECQUELIN-MONOD Aurore, « Mais j'ai transmis l'espérance... Étude d'une prière de guérison tzeltal », Amerindia, vol. 14 (suplemento 113 pp.), 1989.

CROCKER Christopher, « Hombre mono con ojos metal : maneras bororo de apodar a los otros », en LEÓN-PORTILLAet al. (eds.), De Palabra y Obra en el Nuevo Mundo, Vol. 1. Madrid, Siglo XXI, 1992, pp. 237-264.

GARCIA RUIZ Jesús, «La noción de persona entre los mochos » Comunicación en el Coloquio de religión mesoamericana, México, Universidad Nacional Autónoma de México, 1985.

GINZBURG Cario, El queso y los gusanos, Barcelona, Muchnik, 1981.

GOSSEN Gary, «Animal Souls and Human Destiny in Chamula » en Man, vol. 10, 1975, pp. 448-461.

GRUZINSKI Serge, La colonización de lo imaginario. México, Fondo de Cultura Económica, 1991.

GUITERAS holmes Calixta, Los peligros del alma. Visión del mundo de un tzotzil. México, Fondo de Cultura Económica, 1965. 
HERMITTE Esther, Control social y poder sobrenatural en un pueblo maya contemporáneo, México, Instituto Indigenista Interamericano, 1970.

HoLland William, Medicina maya en los Altos de Chiapas, México, Instituto Nacional Indigenista, 1978.

KOHLER Ulrich, Chonbilal ch'ulelal. Alma Vendida. Elementos fundamentales de la cosmología y religión mesoamericanas en una oración en maya-tzotzil, México, Universidad Nacional Autónoma de México, 1995

LE GOFF Jacques, El nacimiento del Purgatorio, Madrid, Taurus, 1981.

LEÓN-PORTILLA Miguel, « Testimonios náhuas sobre la conquista espiritua 1 », Estudios de Cultura Náhuatl, vol. 11, 1978, pp. 155-169.

LÓPEZ AUSTIN Alfredo, Cuerpo humano e ideología. Las concepciones de los antiguos náhuas, 2 vols., México, Universidad Nacional Autónoma de México, 1973.

LÓPEZ AUSTIN Alfredo, Tamoanchan y Tlalocan, México, Fondo de Cultura Económica, 1994.

MAURER Eugenio, Los tseltales. ¿Paganos o cristianos ? Su religión, ¿sincretismo o síníesis ?, México, Centro de Estudios Educativos, 1983.

MONTAGU Roberta, « Autoridad, control y sanción social en las fincas tzeltales », en Norman MCQUOWN, J. PITT-RIVERS, (eds.). Ensayos de antropología en la zona central de Chiapas, México, Instituto Nacional Indigenista, 1970.

NUÑEZ DE LA VEGA Fray Francisco, Constituciones diocesanas del obispado de Chiapa, edición de M. C. LEón CAZARES y M. H. RUZ, México, Universidad Nacional Autónoma de México, 1988.

PITARCH Pedro, Ch'ulel. Una etnografía de las almas tzeltales, México, Fondo de Cultura Económica, 1996.

RUZ Mario Humberto, Copanaguastla en un espejo. Un pueblo tzeltal en el virreinato, San Cristóbal de Las Casas, Universidad Autónoma de Chiapas, 1985.

VILLA-RojAs Alfonso, Etnografía Tzeltal de Chiapas. Modalidades de una cosmovisión prehispánica, México, Gobierno del Estado de Chiapas, 1990.

VOGT Evon, Ofrendas para los dioses, México, Fondo de Cultura Económica, 1979.

\section{NOTAS}

1. NÚÑEZ DE LA VEGA (1988, p. 294).

2. Sobre las concepciones de la persona en el área mesoamericana en general, véase LóPEZ AUSTIN (1973, en particular sobre las concepciones anímicas de los antiguos nahuas, pp. 197-263, y 1994 pp. 103-167). Sobre los tzeltales de Chiapas véase BRETON y BEQUELIN-MONOD (1989, pp. 8-12); HERMitTE (1970) ; MAURER (1983, pp. 399-415); Ruz (1985, pp. 210-225) y VILLA-ROJAS (1990, pp. 336-459). Sobre los tzotziles de Chiapas véase GOSSEN, (1975); GUITERAS HOLMES (1965) ; HOLLAND (1978) ; KOHLER (1975) y VOGT (1979, pp. 31-51). Sobre los mochos de Chiapas véase GARCía Ruiz (1985). Acerca de la «occiden-talización » de la persona en la Nueva España véase GRUZINSKI (1991).

3. BASCHET Jérôme, en este volumen, pp. 5-30.

4. Heredera lejana de la reducción fundada en el siglo XVI por los frailes de la Orden de Santo Domingo, Cancuc, ubicada en la región de los Altos, es una comunidad indígena de unos 25.000 
habitantes que viven en pequeños parajes situados en una serie de valles comprendidos entre los 2.500 y 500 de altitud. Los cancuqueros son todos hablantes de lengua maya-tzeltal (que en la actualidad cuenta con unos 350.000 hablantes en el estado de Chiapas); subsisten del cultivo del maíz, aunque desde hace unas décadas han comenzado a cultivar en algunas zonas café y miel para su venta. Los datos etnográficos presentados aquí fueron obtenidos en Cancuc en 1989 y 1990.

5. Una versión más completa y detallada sobre los conceptos anímicos entre los tzeltales de Cancuc puede verse en PITARCH (1996).

6. En términos generales, la literatura etnográfica sobre grupos indígenas de lengua tzotzil y tzeltal de la región de Los Altos de Chiapas reconoce convencionalmente la creencia en dos clases de alma. La primera está alojada en el corazón y se describe a veces como la sombra del cuerpo que la aloja; en este tipo de alma residen los sentimientos y ciertas formas de pensamiento. La segunda, denominada a veces nahual, suele ser una coesencia animal $u$ otra clase de ser, por ejemplo meteoros ; entre el cuerpo y esta segunda clase de alma existe una estrecha relación de destino, de forma que si el animal sufre algun tipo de accidente, tambien el cuerpo lo sufrira. Esta distinción de tipos de almas se corresponde, grosso modo, por ejemplo con los siguientes pares de nombres: en Chamula : ch'ulel / chanul (GOSSEN ? 1975); en Zinacantán : ch'ulel / chanul (vOGT, 1979); en San Pedro Chenalhó: ch'ulel / wayhel (GUITERAS HOLMES, 1965); en San Andrés Larraínzar: ch'ulel / wayijel (HollAND, 1978); en Pinola : ch'ulel / nahual (HERMITTE, 1970); en Oxchuc : chulel / lab en Oxchuc (villa-RoJAS, 1990); en San Pablo Chalchihuitán : ch'ulel / holomal ( KOHLER, 1995). Por lo que respecta a la comunidad de Cancuc, los pares anteriores se corresponden con las almas ch'ulel / lab.

7. En la etnografía de los Altos de Chiapas las noticias acerca de un ave en el corazón son más bien escasas, pero existen algunas. En Yochib, una aldea del municipio tzeltal de Oxchuc y cercana a Cancuc, alguien explicó a Villa Rojas que : « el alma que come el nagual es como pollito, si es de niño ; como una gallina, si es de mujer y como gallo si es hombre. A veces esta alma sale a pasear solita $\mathrm{y}$, sin darse cuenta, se asoma al lugar donde se reúnen los naguales; entonces se la comen y la persona a quien pertenece deja de existir » (VILLA ROJAS, 1963, p. 255). Montagu, sobre las almas de los tzeltales que vivían como peones en las fincas ganaderas de Ocosingo : « ... otra es un alma en forma de un ave pequeña que habita en el corazón» $(1970$, p. 361). Guiteras, sobre Chenalhó, municipio tzotzil lindante con Cancuc, hace también una breve mención : «En cierta ocasión, Manuel describió el alma que es comida como un pájaro o un ave de corral » (GUTTERAS, 1965, p. 244).

8. En el vocabulario tzeltal de Fray Domingo de Ara, compilado en el siglo XVI, el dominico tradujo chulel por « alma », « suerte », « dicha », " ventura » (Ruz, p. 218).

9. En varios trabajos sobre comunidades de lengua tzotzil se menciona la existencia de estas montañas de almas, aunque tanto HOLLAND (1978, p. 105) como voGT (1979, pp. 38-39) explican que aqui las almas se encuentran bajo la forma de animales. Sin embargo, Esther HERMITTE (1970) en su etnografía sobre Pinola, una comunidad de lengua tzeltal, explica, refiriéndose al ch'ulel, que traduce como «espíritu »: «El espíritu está en el corazón o en la garganta y al mismo tiempo mora en las cuevas » (ibid, p. 49). Esta cueva, Muk' Nah (es decir, « Casa Grande »), « es donde está el gobierno'. Están los me'iltatiles que tienen secretario, policías y un juez para decidir sobre el destino de sus subditos y espantar al mal que viene de fuera. En Muk' Nah no vive ningún tigre, ni gallinas, ni monos » (ibid, p. 49). Por tanto en esta comunidad las almas que están desdobladas en la montaña carecen de forma animal.

10. Por indemostrable que sea, no puede descartarse enteramente que en la formación de los detalles del ch'iibal hayan intervenido en el pasado las descripciones cristianas del cielo, el infierno y, sobre todo quizá, del purgatorio. Según LE GOFF (1981, p. 129) la montaña es un elemento geográfico esencial para la localización del purgatorio, como en la obra de Dante. 
11. MAURER (1983, p. 401) cita brevemente este tipo de lab en su etnografía de Guaquitepec.

12. En líneas generales, los cancuqueros distinguen dos categorías de especialistas médicos. Los poxtaywanej están especializados en la extracción de objetos que provocan la enfermedad. Los ch'abajometik, por su parte, se ocupan de las afecciones anímicas. Estos últimos se distinguen por que trabajan en los altares domésticos, ofreciendo substancias de valor (incienso de copal, tabaco, aguardiente, oraciones) a los espíritus que secuestran el ch'ulel a cambio de este, o bien a las autoridades de la montaña ch'iibal.

13. GINZBURG(1981).

14. En otro trabajo (PITARCH, 1996) he tratado este fenómeno de interiorización del pasado bajo formas anímicas en lugar de narrativas.

15. LEON-PORTILLA (1978, pp. 162-163)

16. De hecho, no existe en lengua tzeltal un termino tan inclusivo como el francés " mort ». Se emplean, de manera mutuamente exclusiva, los vocablos laj, para la muerte « natural », es decir por enfermedad, cuyo sentido es el de acabarse algo o alguien, y mil para las muertes violentas, como en el caso de asesinato o de suicidio.

17. BASCHET, op. cit., p. 13.

18. Entre los indígenas tzeltales, la relación correcta entre los sexos separa a los hombres de los animales y también hasta cierto punto de los europeos, quienes en sus relaciones amorosas se comportan como los perros.

19. BASCHET, op.cit., p. 8.

20. CROCKER (1992, p. 242).

\section{RESÚMENES}

En la perspectiva de los indígenas tzeltales de la región de los Altos de Chiapas, en el sudeste de México, la persona se halla compuesta por un extenso conjunto de « almas ». Estas representan un heterogéneo repertorio de seres (animales, meteoros, espíritus, monstruos, etc.) que se encuentran diseminadas por el mundo $\mathrm{y}$, simultáneamente, instalados en el interior del cuerpo. En este articulo se plantea la siguiente pregunta : si, de acuerdo con la concepción indígena, el mundo se halla plegado sobre la persona ¿en qué se distinguen los seres humanos del resto de seres animados? De manera tentativa, la respuesta es : el cuerpo humano. Para los indígenas tzeltales, el cuerpo (a diferencia de las almas, que están dadas desde el nacimiento individual) se va formando a lo largo de la vida, como resultado del dominio gestual, del habla y de las practicas culinarias. El fin del cuerpo, la muerte, significa la deshumanización de la persona.

For the Tzeltal Indians of the Chiapas Highlands area, in southeast Mexico, the self is composed by an extensive set of " souls ». These represent an hete rogeneous repertoire of beings (animals, meteors, spirits, monsters, etc.) that are diseminated across the World, and, simultaneously, within the human body. This essay addresses the following question : if, according to the Indian conception, the world is folded into the self, what is that distinguishes the human being from other animated beings? Tentatively, the answer is the Human Body. For the Tzeltal Indians, the body (in contrast with the souls, which are given since birth) is formed through the individual life, as the result of the gestural, speech and food practices control. Death, the end of the body, implies, accordingly, the dehumanization of the self. 
D'après les indigènes tzeltals de la region des Hauts Chiapas, au sud-est de Mexico, la personne est composée d'un vaste ensemble "d'âmes ». Elles représentent un repertoire hétérogène d'êtres (animaux, météores, esprits, monstres, etc.) simultanément dispersés a travers le monde et installés a l'intérieur du corps. L'articlepose la question suivante: si, en accord avec la conception indigène, le monde se trouve replié dans la personne, qu'est-ce qui distingue les êtres humains des autres êtres animés? On peut tenter de répondre: le corps humain. Pour les indigènes tzeltals, le corps (à la différence des ames qui sont attribuées à chacun des la naissance) se construit tout au long de la vie, comme résultat de la gestuelle, de la parole et des pratiques culinaires. La fin du corps, la mort, signifie la deshumanisation de la personne.

\section{AUTOR}

\section{PEDRO PITARCH}

Universidad Complutense de Madrid 